\title{
Geogrid Mechanical Damage Caused by Recycled Construction and Demolition Waste (RCDW): Influence of Grain Size Distribution
}

\author{
M.L. Domiciano, E.C.G. Santos, J. Lins da Silva
}

\begin{abstract}
Recent studies have shown that recycled construction and demolition waste (RCDW) can be used as backfill material in geosynthetics reinforced soil (GRS) structures. However, besides the environmental and economic benefits of this practice, it is necessary to evaluate the mechanical damages that RCDW could cause to the reinforcement elements. This study aims to investigate the influence of RCDW grain size distribution on short-term geosynthetic mechanical damages. The RCDW used in this investigation was collected at a recycling plant and the geosynthetics consisted of geogrids usually employed in GRS structures. In order to simulate the mechanical damages, a steel box was used and the applied loads within the magnitudes of values normally observed in this type of engineering work. The results showed no significant reduction for tensile strength of geogrids. On the other hand, it was possible to notice the effects of loading process on strain at rupture and stiffness. However, the reduction factors obtained from the damaged geogrids could be applied during GRS design stage. This study concludes that the damages caused by RCDW to geogrids would not prevent the use of this new composite in several engineering works.
\end{abstract}

Keywords: debris, durability, geosynthetics, granulometry, loading process, sustainability.

\section{Introduction}

Due to its need of using a tremendous variety of materials and processes, the construction industry plays a significant role in environmental issues, not just as a domestic industry, but on a global scale. The construction industry stands pointed out as one of the largest producers of solid waste on the planet, being responsible for over 10 billion tons generated worldwide every year (Wu et al., 2019). Therefore, preventing environmental, economic, and social impacts caused by the construction and demolition wastes (CDW) demands attitude changes in order to turn the efficient management and reuse of these wastes into worldwide goals.

In this context, geosynthetics appear as modern and environmentally friendly products derived from researches and development of the polymer industry and geotechnical engineering. These materials have been increasingly used in geotechnical engineering due to their economic and environmental benefits. Over the last decades, geosynthetic reinforced soil (GRS) walls have presented a series of positive ecological parameters when compared to traditional concrete cantilever walls (Jones, 1994), which include $40 \%$ less $\mathrm{SO}_{2}$ released into the atmosphere during the fabrication of their component parts.
Reinforcement material durability is an important issue related to the design and performance of GRS walls. Therefore, besides promoting good interaction with the geosynthetic, the filling material is expected to be biochemically and mechanically low-aggressive. Bearing in mind theses aspects, even though the proposal of using recycled construction and demolition waste (RCDW) as backfill material in GRS structures seems to be an interesting strategy to promote the concept of sustainable development in Civil Engineering, it is crucial to investigate the eventual damages caused by this non-conventional filling material in a field condition.

\subsection{Characteristics of RCDW grain}

The definition of CDW is not a consensus, varying from one country to another. But, apart from some peculiar local construction characteristics, the CDW consist of a mixture of different materials: i) ceramics, ii) concrete blocks, iii) mortar, iv) steel, v) plastic, vi) wood and others. The diversity of materials composing the CDW and the different procedures adopted at recycling plants lead up to products with different properties and grain size distribution (Kartam et al., 2004; Esin \& Cosgun, 2007; Angulo et al., 2011; Leite et al., 2011; Ossa et al., 2016).

Marcela L. Domiciano, M.Sc., Assistant Professor, Departamento de Engenharia Civil, Centro Universitário de Goiânia, Av. T-02, 1993, 74215-005, Goiânia, GO, Brazil. E-mail: marcelaleaodomiciano@gmail.com.

Eder C.G. Santos, D.Sc., Associate Professor, Escola de Engenharia Civil e Ambiental da Universidade Federal de Goiás, Avenida Universitária, nº 1488, Qd. 86, Setor Universitário, 74.605-220 Goiânia, GO, Brazil. E-mail: edersantos@ufg.br.

Jefferson Lins da Silva, D.Sc., Associate Professor, Escola de Engenharia de São Carlos (EESC) da Universidade de São Paulo, Avenida Trabalhador São-Carlense, 400, Pq Arnold Schimidt, 13.566-590 São Carlos, SP, Brazil. E-mail: jefferson@sc.usp.br.

Submitted on March 16, 2020; Final Acceptance on April 6, 2020; Discussion open until September 30, 2020.

DOI: $10.28927 /$ SR.432231 
The granulometric variability of RCDW sampled at recycling plants has been reported in some geotechnical investigations (Santos, 2007; Barbosa, 2017; Santos et al., 2013; Fleury, 2018; Silvestre, 2019) and maximum values (highest coefficient of variation of material percentage passing through a specific mesh aperture) were noted, ranging from $15 \%$ (Barbosa, 2017) to $109 \%$ (Silvestre, 2019). Given that the grain size distribution of RCDW is one of the features that affect the degree of interlocking between its particles, hence affecting the contact area, the evaluation of the granulometric variability can help indicate how standardized it will be.

Another important factor that affects the interlocking characteristic of particulate media is the particle shape. The results reported by Leite et al. (2011) revealed that RCDW composition influenced the shapes of the grains - cementitious materials and crushed rocks have a wide predominance of cubic grains - and the particles presented a higher percentage of cubic grains after compaction test. The study concluded that cubic particles could contribute to better densification and higher shear strength. On the other hand, flat and elongated particles would be more susceptible to breaking when compacted. When testing individual RCDW grains, it was possible to verify that particle shapes play a more prominent role in particle breakage phenomena than mineralogy and microstructure (Afshar et al., 2017).

\subsection{Geosynthetic mechanical damages caused by RCDW}

The reduction of geogrid ultimate tensile strength $\left(T_{u l t}\right)$ due to installation damage becomes a problem for determining its allowable tensile strength $\left(T_{a l}\right)$. To deal with the damage caused by installation activities, and others which geosynthetics are exposed to, GRS structure designers consider the application of reduction factors to determine $T_{a l}$, according to (Allen \& Bathurst, 1996):

$$
T_{a l}=\frac{T_{u l t}}{R F}=\frac{T_{u l t}}{R F_{I D} \cdot R F_{C R} \cdot R F_{D}}
$$

where $T_{u l t}$ is the ultimate tensile strength; $R F$, the global reduction factor; $R F_{I D}$ is the installation damage reduction factor; $R F_{C R}$, the creep reduction factor; and $R F_{D}$ is the durability reduction factor. The $R F_{I D}$ is calculated according to

$$
R F_{I D}=\frac{T_{u l t_{-} v}}{T_{u l t_{-} d}}
$$

where $T_{\text {ult_v}}$ and $T_{\text {ult_d}}$ represent the ultimate tensile strength mean value of virgin (undamaged) and damaged specimens, respectively.

This damage can be more severe when geogrids are used together with larger size aggregate particles and compacted with high energy (Huang \& Wang, 2007; PinhoLopes; Lopes, 2014; Fleury et al., 2019). Mechanical dam- age to geosynthetics can be evaluated by i) tensile strength, ii) strain at rupture and ii) secant stiffness, from the curves tensile strength against strain obtained in laboratory tensile tests (Allen \& Bathurst, 1994).

Some researchers (Paula et al., 2004; Huang, 2006; Huang \& Chiou, 2006; Huang \& Wang, 2007; Yoo et al., 2009; Rosete et al., 2013; Gonzalez-Torre et al., 2014) carried out the standard laboratory test, according to EN ISO 10722:2007 (BSI, 2007), focused on assessing the mechanical damage to geogrids under repeated loading with granular materials. The values of reduction factors for mechanical damages $\left(R F_{M D}\right)$, for different repeated loads and granular materials, ranged between 0.93 and 1.54.

Mechanical damages caused by RCDW to geosynthetic reinforcement elements used in an in-field experimental large-scale wall were investigated by Santos $e t$ al. (2012). The RCDW collected in a construction site located in Brasília, Brazil, consisted of demolition waste submitted to primary crushing in order to reduce its particle size. The geotechnical characterization showed that the RCDW was classified as a sandy gravel. Based on a statistical analysis proposed by Santos (2011), the results revealed that different compaction procedures (lightweight roller or vibratory hammer) caused distinct damages to polyester (PET) geogrid (GG) $\left(T_{u l t}=20 \mathrm{kN} / \mathrm{m}\right)$.

An investigation of the effects of dropping height $(0.0 \mathrm{~m}, 1.0 \mathrm{~m}$ and $2.0 \mathrm{~m})$ and compaction procedure (vibratory plate) on the mechanical damages of a polyester (PET) geogrid $\left(T_{u l t}=35 \mathrm{kN} / \mathrm{m}\right)$ revealed that the RCDW, classified as gravely sand, caused damages with low or very low magnitudes, considering all the scenarios investigated (Barbosa \& Santos, 2013).

In a recent study, Fleury et al. (2019) investigated the occurrence of mechanical damage during the installation of geogrids in an in-field test facility with RCDW backfill material. The results showed that the variation of dropping height $(0.0 \mathrm{~m}, 1.0 \mathrm{~m}$, and $2.0 \mathrm{~m})$ caused a slight reduction in the ultimate tensile strength $\left(T_{u l t}\right)\left(R F_{I D}=0.94\right.$ to 1.21$)$. However, the authors also observed that compaction methods were a relevant factor for geogrid installation damage in most of the investigated scenarios, with $R F_{I D}$ ranging from 0.98 to 1.22 , with the vibratory hammer compaction promoting the highest reduction effect.

Despite the contribution made by laboratory and infield tests, the investigation of mechanical damage to geosynthetic products caused by non-conventional material brings together the need to evaluate some issues so far not assessed. Bearing in mind the proposal of using RCDW as backfill material, the evaluation of grain size distribution may raise another aspect that could affect the level and way mechanical damages occur to geosynthetic products: particle breakage during the loading process. Therefore, this paper aims to evaluate and quantify the effect of grain size distribution curves on RCDW breakage and its consequence for the mechanical damage caused to geogrids. 


\section{Materials and Methods}

\subsection{Materials}

\subsection{1. $R C D W$}

The RCDW used in this investigation were produced by a recycling plant in Aparecida de Goiânia-GO, Brazil. The recycling plant uses a jaw crusher, in a single operation, to reduce the particle size of CDW and to produce different materials, such as: i) Aggregate A $(9.5 \mathrm{~mm}>d>$ $4.75 \mathrm{~mm})$, ii) Aggregate B (19 mm $>d>9.5 \mathrm{~mm})$, iii) Aggregate $\mathrm{C}(d<19 \mathrm{~mm})$, iv) Aggregate $\mathrm{D}(d>19 \mathrm{~mm})$, v) Sand A $(d<4.75 \mathrm{~mm}$, sand composed of crushed CDW), vi) Sand B $(d<4.75 \mathrm{~mm}$, sand composed of crushed concrete) and vii) By-product. Bearing in mind the aims of this study and size limitations of the test box, the RCDW were selected based on their potential to be used as backfill material in GRS structures.

Three types of recycled products were investigated: i) Aggregate A, ii) Aggregate B and iii) Aggregate C (Fig. 1). According to the manufacturer, Aggregate $\mathrm{C}$ is composed of equal volumes of Aggregate A, Aggregate B and Sand B. It is important to point out that Aggregate $\mathrm{C}$ represents around $44 \%$ of the products sold by the recycling plant nowadays.

\subsubsection{Geosynthetics}

To investigate the influence of geogrid structure on the strength against mechanical damages, tests were carried out with three types of geogrids, being one composed of polyvinyl alcohol yarns (GGPVA, $T_{u l t}=35 \mathrm{kN} / \mathrm{m}$; mass per unit area, $M_{A}=160 \mathrm{~g} / \mathrm{m}^{2}$ ) and two others of polyester yarns
(GGPET 01, $T_{u l t}=55 \mathrm{kN} / \mathrm{m}, M_{A}=280 \mathrm{~g} / \mathrm{m}^{2}$; GGPET 02, $\left.T_{u l t}=35 \mathrm{kN} / \mathrm{m}, M_{A}=185 \mathrm{~g} / \mathrm{m}^{2}\right)$. These geogrids are usually used as reinforcement elements in GRS structures. Figure 2 presents the images of the geogrids.

The dimensions of the geogrid specimen submitted to tensile strength testing consisted of $200 \mathrm{~mm}$ (transversal direction) by 1,200 $\mathrm{mm}$ (longitudinal direction). The processes of storage, transportation and cutting of the geogrid specimens were carried out carefully to avoid any damages to the virgin samples, as well as any additional damages to the tested specimens.

\subsection{Experimental program}

\subsection{1. $R C D W$ characterization}

For each kind of RCDW, five samples were collected at one-monthly intervals trying to verify eventual variability of the recycled products, and the sampling procedure was carried out in different parts of the waste pile (bottom, middle and top). The laboratory tests followed the Brazilian standards and consisted in those usually performed for soil characterization: i) specific gravity (NBR 6458, ABNT, 2016a), ii) grain size distribution (NBR 7181, ABNT, 2016b), iii) Atterberg limits (NBR 6459, ABNT, 2016c; NBR 7180, ABNT, 2016d), iv) compaction test (Standard Proctor) (NBR 7182, ABNT, 2016e), and v) gravimetric composition.

Once the RCDW samples were sieved before and after each test of damage reproduction, it was possible to compare grain size distribution curves and particle shapes before and after the loading process. The use of a microscope also aimed to identify the roughness of RCDW particles.

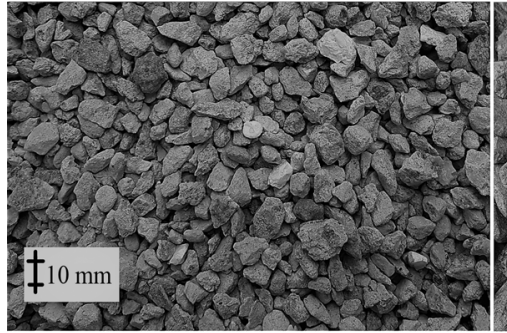

(a)

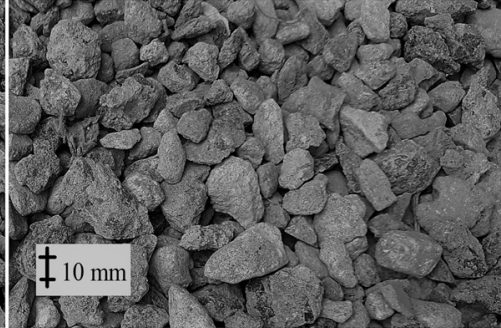

(b)

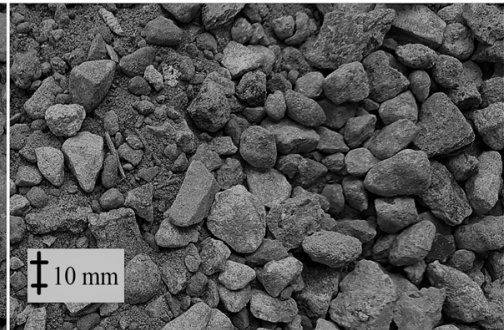

(c)

Figure 1 - RCDW: a) Aggregate A, b) Aggregate B and c) Aggregate C.

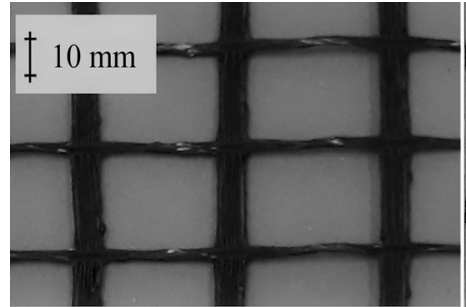

(a)

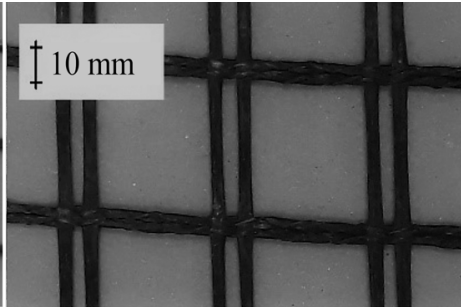

(b)

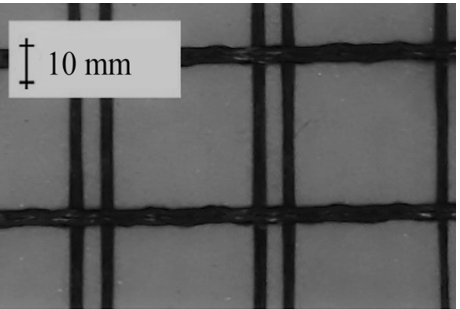

(c)

Figure 2 - Geogrids: a) GGPVA, b) GGPET 01 and c) GGPET 02. 
The gravimetric composition was carried out according to the procedure presented by Santos (2007). Initially, $10.0 \mathrm{~kg}$ of Aggregate $C$ were sieved on a mesh of $4.75 \mathrm{~mm}$ under running water; the retained material was left to dry in an oven for at least $12 \mathrm{~h}$; finally, the retained material was sorted by visual analysis (naked eye) according to the different gravimetric compositions. Particles of RCDW smaller than $4.75 \mathrm{~mm}$ (including those removed during the washing process) were classified as 'soil'.

The procedure of evaluating the shape and roughness of RCDW particles, consisting of visual analysis by means of a digital microscope, was used to verify the shape and surface roughness of the RCDW particles. The equipment used has magnification ranging from $5 \times$ to $100 \times$. The images of coarse grains (dimensions varying from $2.0 \mathrm{~mm}$ to $10.0 \mathrm{~mm}$ ) were taken using a magnifying glass.

\subsubsection{Laboratory damage reproduction}

The mechanical damage was carried out reproducing the loading process using a steel-made box (440 long $\times 300$ wide $\times 300 \mathrm{~mm}$ high) which is divided into two parts (upper and bottom). At the middle height, the test box has an aperture for geosynthetic installation. Figure 3 shows the equipment dimensions in a perspective view. The mechanical damage tests were performed with the last collected samples of each kind of aggregate (nominated 'samples \#5').

The test procedure consisted of placing the RCDW (dry condition) in the test box up to its medium height (bottom part completely filled). Then, the RCDW was statically compacted (one-dimensional compression) using a universal testing equipment until the material achieved a compaction degree approximately equal to $85 \%$ (Standard Proctor) - Fleury et al. (2019) reported a value of $89 \%$ when compacting recycled materials from the same recycling plant with a vibratory roller. Then, the central part of the geogrid specimen ( $300 \mathrm{~mm}$ long and $200 \mathrm{~mm}$ wide) was laid in contact with the RCDW - the extreme portions of the geogrid remained outside the box and not damaged. Finally, the upper part of the test box was positioned, filled up with

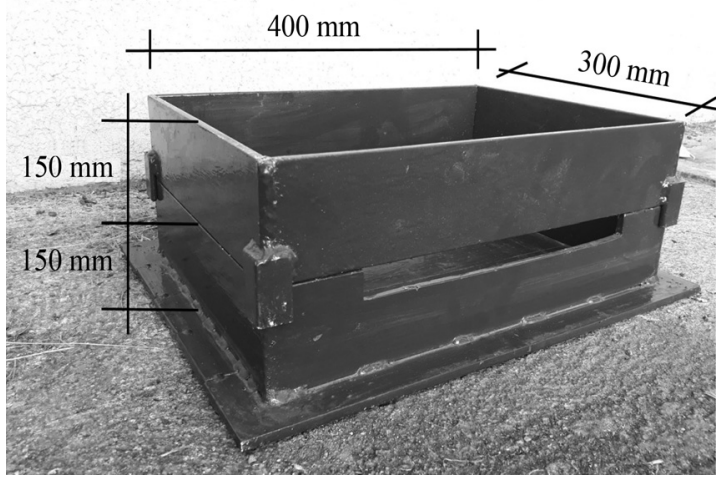

Figure 3 - Test box perspective view and dimensions.
RCDW and also statically compacted to the same degree of compaction.

Once the test box had been totally assembled, the normal stress was applied (increment of $10.2 \mathrm{kN} / \mathrm{min}$ ) on a steel plate of $20 \times 200 \times 340 \mathrm{~mm}$ using the universal testing equipment. Considering a GRS higher than $10.0 \mathrm{~m}$ and eventual external loads, tests were carried out with $150 \mathrm{kPa}$, $300 \mathrm{kPa}$, and $600 \mathrm{kPa}$. Once achieved the intended load, it was kept for $5 \mathrm{~min}$ - enough time to stabilize plate displacement detected by monitoring instruments. Bearing in mind the variability of RCDW, five tests (non-reuse) were performed for each load, which resulted in a total amount of 135 specimens.

Following that, the specimens were carefully exhumed to prevent the occurrence of additional mechanical damages, properly identified and submitted to tensile tests this last one, at São Carlos School of Engineering (EESC), University of São Paulo (USP). The tensile tests were carried out according to ASTM D-6637-15 - Standard Test Method for Determining Tensile Properties of Geogrids by the Single or Multi-Rib Tensile Method (ASTM, 2015). Figure 4 shows the executive sequence of the damage simulation test.

\subsubsection{Validation and quantification of damage}

To determine valid the occurrence of damage, the method proposed by Santos (2011) was used with the reduction factors (RF) being calculated considering the variability of virgin specimens. According to the method, the confidence interval (nominated $F_{0}$ ) of the properties of in-

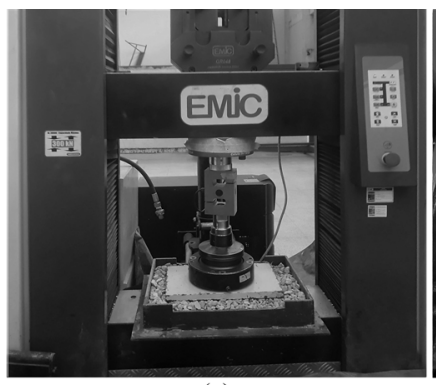

(a)

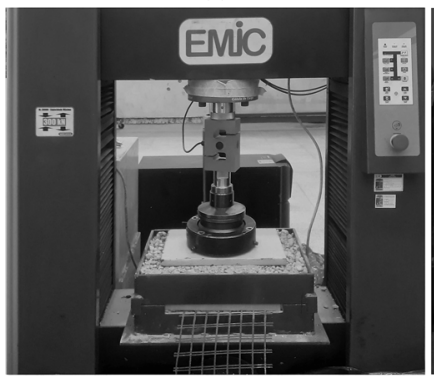

(c)

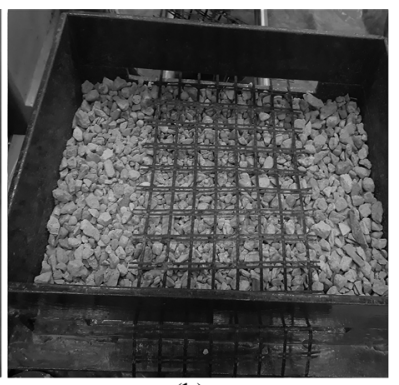

(b)

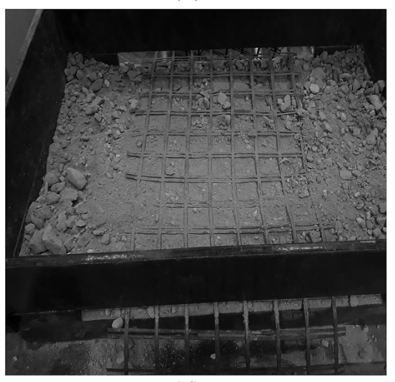

(d)
Figure 4 - Executive sequence: a) static compaction of RCDW in the box bottom part, b) geosynthetic laid in contact with the $\mathrm{RCDW}, \mathrm{c}$ ) application of load during the test, d) exhumation of geogrid specimen. 
terest $\left(T_{u l t}, \varepsilon_{r u p}\right.$, and $\left.J_{s e c}\right)$ was obtained from the tests of virgin specimens using Student's $t$-distribution with the sample mean value confidence given by

$$
t=\frac{\bar{X}-\mu}{\frac{S}{\sqrt{n}}}
$$

where $t$ is the value of the Student's $t$-distribution variable, $\bar{X}$ is the mean value of the virgin sample; $\mu$, the population mean; $S$, sample standard deviation; and $n$ is the sample size.

To calculate the value of $R F$, two scenarios were evaluated: i) the damaged sample mean value $\left(\bar{X}_{d}\right)$ into the virgin sample confidence level interval raises doubt about the occurrence of damage, hence the reduction factor was assumed as equal to 1.0 ; ii) in the case of the damaged sample mean value $\left(\bar{X}_{d}\right)$ out of the virgin sample confidence level interval, the reduction factor was calculated according to

$$
R F_{X}=\frac{\bar{X}}{\bar{X}_{d}}
$$

where $R F_{X}$ is the reduction factor related to the $X$ parameter, $\bar{X}$ is the virgin sample mean value of the analyzed parameter and $\bar{X}_{d}$ is the damaged sample mean value of analyzed parameter.

\section{Results and Discussion}

\subsection{Recycled construction and demolition waste}

\subsubsection{Granulometric analysis}

The grain size distribution curves of RCDW showed a significant variability, which made the samples be better evaluated using a 'grain size distribution range'. These results revealed that the procedures adopted at the recycling plant presented different levels of efficiency, being less efficient (higher variability) when involving processes of mixture of some products for producing a new one. Another factor that must be pointed out is related to the weather conditions during the recycling process, given that samples of Aggregate A (A-A \#3 and \#4), collected on rainy days, showed higher amount of fine materials. Figures 5 to 7 present the grain size distribution curves of investigated recycled aggregates and show the grain size distribution ranges for each sample of RCDW. Table 1 presents RCDW classification according to the Unified Soil Classification System (USCS) - (ASTM, 2017).

\subsubsection{Gravimetric composition}

The gravimetric composition analysis revealed that approximately $98 \%$ of the composite materials of Aggregate $\mathrm{C} \# 1$ can be classified as inert materials (soil, concrete, ceramic materials, and natural gravel), with no more than $2 \%$ composed of metal, wood, paper, plastic and other materials - similar results have been found by Herrador et al.
(2012) and Santos et al. (2013, 2014). Percentages of soil, Portland cement concrete and ceramics showed significant values of coefficient of variation ( $\mathrm{COV}$ ) equal to $45.19 \%$, $27.90 \%$ and $70.92 \%$, respectively. Figure 8 shows the results of the gravimetric composition analysis of the Aggregate $\mathrm{C}$ samples.

The variation of soil amount in the RCDW composition can be justified by the fact that buildings in the

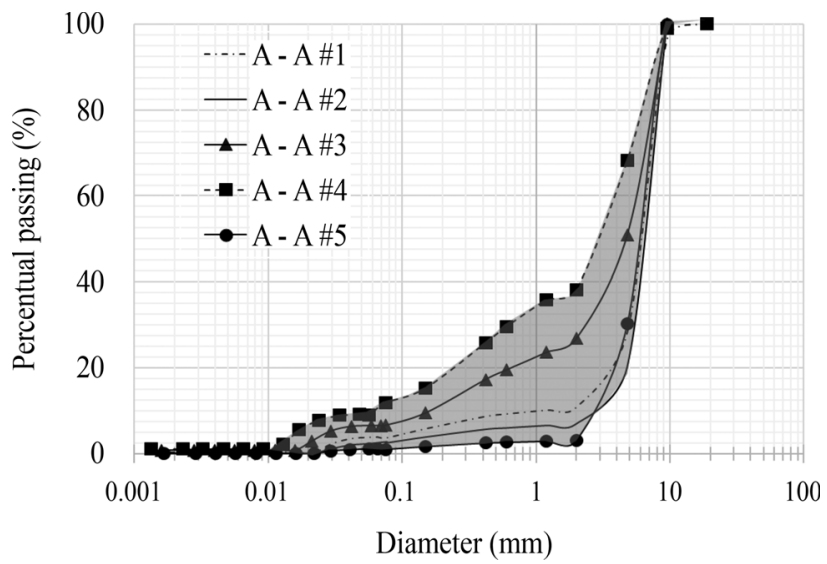

Figure 5 - Aggregate A grain size distribution curves.

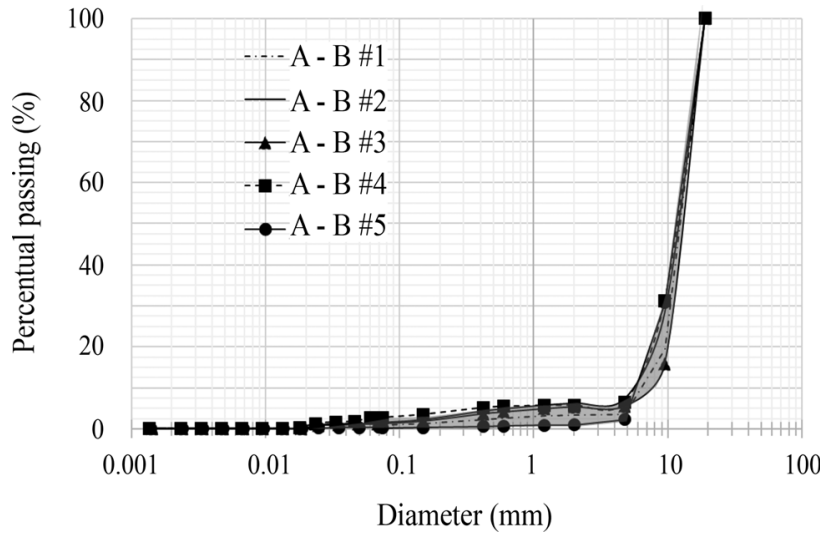

Figure 6 - Aggregate B grain size distribution curves.

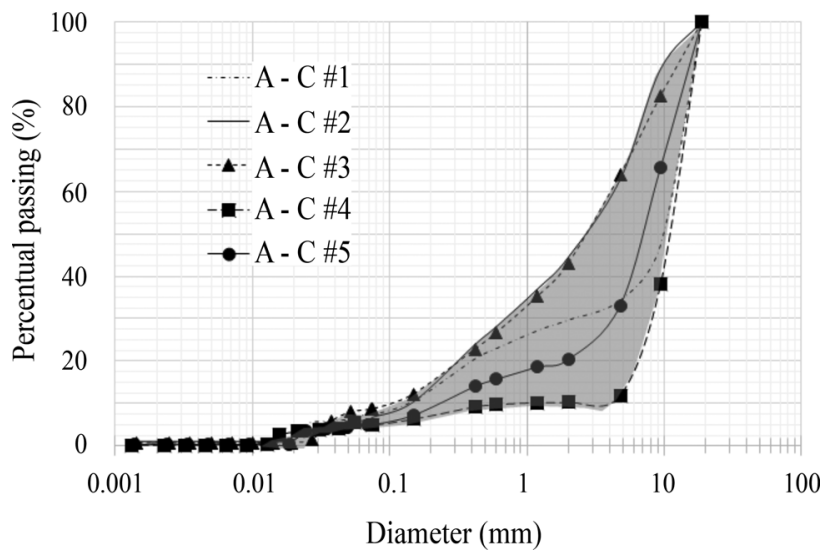

Figure 7 - Aggregate C grain size distribution curves. 
Table 1 - Classification of the RCDW according to the USCS system.

\begin{tabular}{lccc}
\hline Sample & Aggregate A & Aggregate B & Aggregate C \\
\hline$\# 1$ & GP-GM with sand & GP & GW-GM with sand \\
$\# 2$ & GP with sand & GP & SW-SM with gravel \\
$\# 3$ & SP-SM with gravel & GP & SW-SM with gravel \\
$\# 4$ & SW-SM with gravel & GP & GP-GM with sand \\
$\# 5$ & GP with sand & GP & GP-GM with sand \\
\hline
\end{tabular}

Note: $\mathrm{GW}=$ well graded gravel; $\mathrm{GP}=$ poorly graded gravel; $\mathrm{GM}=$ silty gravel; $\mathrm{SW}=$ well-graded sand, fine to coarse sand; $\mathrm{SP}=$ poorly graded sand; $\mathrm{SM}=$ silty sand.

metropolitan area where the recycling plant is located possess underground structures (underground garage, for example), once the deep water table verified at the region allows this type of construction. Therefore, this kind of underground construction is responsible for a significant amount of excavated soil sent to the recycling plant.

The variation of Portland cement concrete and ceramic materials amount reveals, besides the main construction characteristics of the local buildings, the lack of waste management in the construction site. Given that the constructions have several types of materials, such as reinforced concrete, metallic structures, wood, soil, tile, bricks, etc., these materials should be submitted to a process of segregation/separation in the construction site. However, at present, the segregation process is not carried out in most construction sites in Goiânia-GO, Brazil.

\subsubsection{Specific gravity}

Due to the diverse materials found in RCDW, the specific gravity $\left(G_{s}\right)$ of i) particles passing in the $4.75-\mathrm{mm}$ sieve and ii) particles passing in the $19-\mathrm{mm}$ sieve and retained by the $4.75-\mathrm{mm}$ sieve were investigated. Results showed that the mean value of $G_{s}$ for the particles passing in the $4.75-\mathrm{mm}$ sieve was practically the same for Aggregate B $\left(2.602 \mathrm{~g} / \mathrm{cm}^{3}, C O V=0.54 \%\right)$ and Aggregate C $\left(2.603 \mathrm{~g} / \mathrm{cm}^{3}, C O V=3.28 \%\right)$; and Aggregate A presented a mean value approximately $20 \%$ smaller than the other materials $\left(G_{s}\right.$ equal to $\left.2.166 \mathrm{~g} / \mathrm{cm}^{3}\right)$.

The $G_{s}$ of the grains retained in the $4.75-\mathrm{mm}$ sieve, considering the three materials (A-A, A-B, and A-C) showed mean values ranging from $2.658 \mathrm{~g} / \mathrm{cm}^{3}$ to $2.684 \mathrm{~g} / \mathrm{cm}^{3}$, similar to the ones reported by Santos \& Leite (2018) and approximately $21 \%$ higher than those presented by Angulo et al. (2011). This fact can be justified by the different focus given to the RCDW studied, since the latter au-

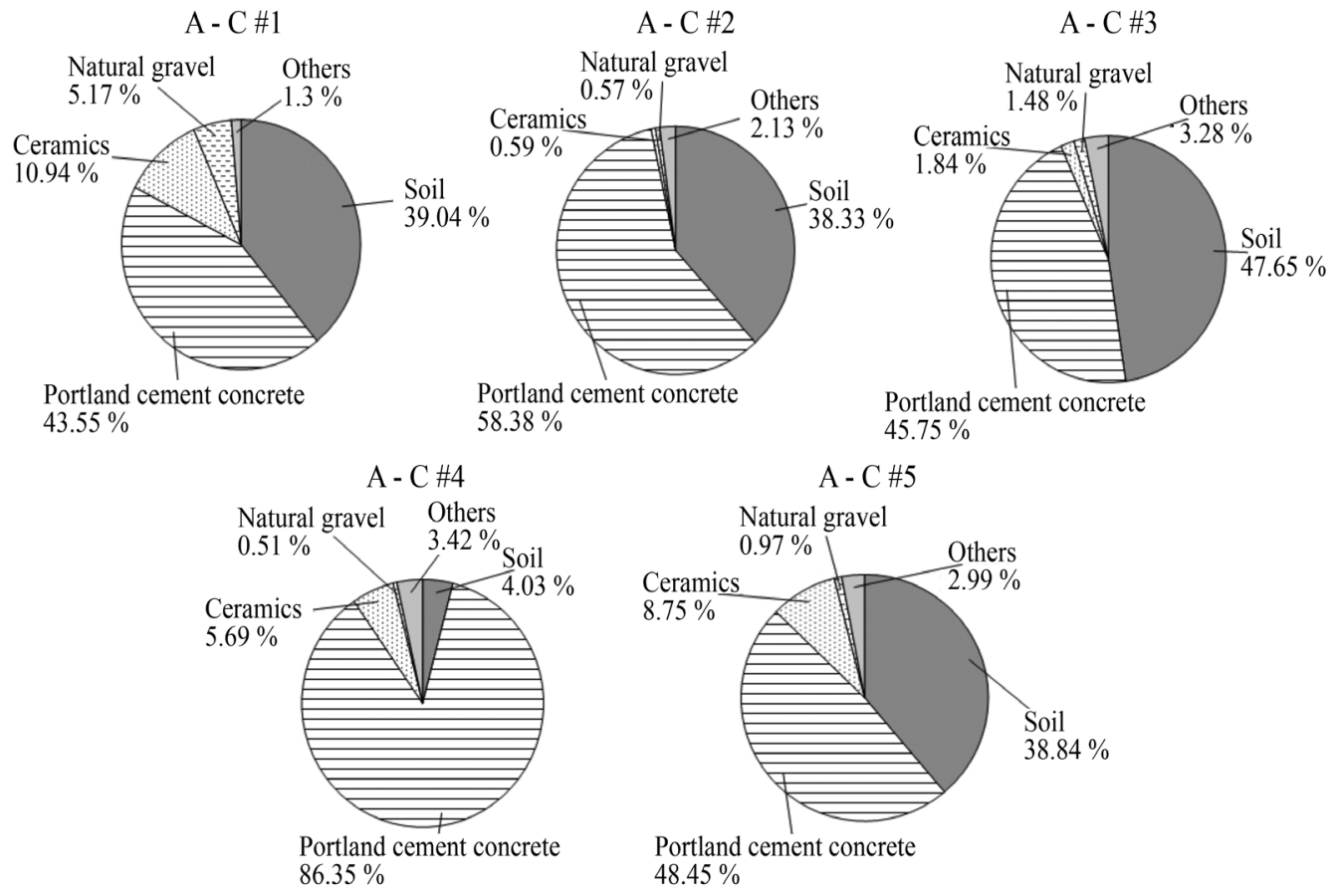

Figure 8 - Percentage of composite materials. 
thors investigated the use of recycled aggregates in nonstructural concrete.

The results revealed low variability of $G_{s}$ of the RCDW. The variability of the material passing in the $4.75-\mathrm{mm}$ sieve ranged from $0.54 \%$ to $4.21 \%$, and the variability of the material retained in the $4.75-\mathrm{mm}$ sieve (and passing the 19 -mm sieve) ranged from $0.27 \%$ to $1.63 \%$.

It was observed that Aggregate $\mathrm{C}$ presented considerable amount of soil in its composition. Previous studies on the local soil (tropical soil) revealed values of $G_{s}$ varying from $2.664 \mathrm{~g} / \mathrm{cm}^{3}$ (Silva et al., 2019) to $2.740 \mathrm{~g} / \mathrm{cm}^{3}$ (Mascarenha et al., 2018). Aggregate A visibly exhibited a greater amount of ceramic material, which is probably responsible for the reduction of its $G_{s}$.

\subsubsection{Atterberg limits}

All the samples presented non-plastic behavior, which can be explained by the fact of having low presence of clay particles (diameter $<0.002 \mathrm{~mm}$ ). These results also follow those found by Santos et al. $(2013,2014)$ and Ossa et al. (2016). It is worth mentioning that these results validate the application of RCDW as backfill material in GRS, according to the recommendation of BSI 8006 (2010).

\subsubsection{Compaction}

Standard Proctor compaction tests were carried out only on four samples of Aggregate C, once the very low amount of fine material did not allow making the test with sample A-C \#4. Aggregate A and Aggregate B also were not tested for the same reason. Figure 9 and Table 2 present the results of the compaction test carried out without reuse of material.

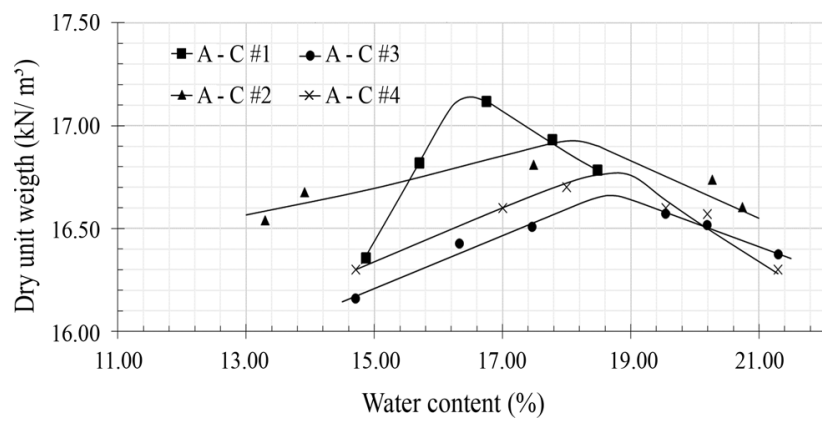

Figure 9 - Compaction test curves - Aggregate C (except sample A-C \#4).
The results of the compaction test revealed the direct influence of ceramic material content. Higher amount of ceramic material causing higher values of optimum water content was observed. These results follow those presented by Silva et al. (2016) and Cardoso et al. (2016). However, sample A-C \#1, despite having the highest content of ceramic aggregates, showed the lower optimum water content. This discrepancy encourages further investigation into the properties of the ceramic materials present in RCDW.

\subsection{Influence of loading process on RCDW properties}

Considering that the process of applying loads of $150 \mathrm{kPa}, 300 \mathrm{kPa}$ and $600 \mathrm{kPa}$ could break the low-resistance particles of RCDW, specific gravity tests carried out and grain size distribution curves were drawn using samples from different loading conditions.

\subsubsection{Characterization of materials}

The results showed that there was no great variation of the values of $G_{s}$ of the recycled materials submitted to different loads in comparison to the one presented by the intact material (without loading), even considering both analyzed particle sizes (passing in the $4.75-\mathrm{mm}$ sieve or retained in the $4.75-\mathrm{mm}$ sieve). Table 3 presents the $G_{s}$ values of tested materials.

The effects of loading on RCDW characteristics were also investigated with grain size distribution analysis of the tested samples. For this purpose, tests were performed on the materials applying different loads and, to show the percentage difference for different samples and scenarios, curves were drawn in comparison to those not submitted to loading (Fig. 10).

It was noticed that the higher the load applied, the greater the quantity of fine grains in all the tested materials. However, it is possible to point out that specific changes were observed. The highest particle size variations for all samples (A-C, A-B, and A-A) occurred around the grain dimensions of $4.75 \mathrm{~mm}$. In general, the grain breakage showed increase up to the diameter of $4.75 \mathrm{~mm}$ and decreased after this diameter.

The Aggregate A appeared as the most sensitive in relation to breakage by increased loading, probably due to its uniform grain size distribution and the presence of some particles of ceramic materials. This statement is strengthened by the results of Aggregate B, which presented smaller breakage value for the different loads. Even though

Table 2 - Maximum dry unit weight and optimum water content - Aggregate C (except sample A-C \#4).

\begin{tabular}{lcccccc}
\hline Property & A-C \#1 & A-C \#2 & A-C \#3 & A-C \#5 & Mean & COV (\%) \\
\hline$\gamma_{d-\max }\left(\mathrm{kN} / \mathrm{m}^{3}\right)^{\mathrm{a}}$ & 17.150 & 16.925 & 16.660 & 16.758 & 16.859 & 1.13 \\
$w_{o p}(\%)^{\mathrm{b}}$ & 17.10 & 18.00 & 18.70 & 19.00 & 17.60 & 4.70 \\
\hline
\end{tabular}

Note: ${ }^{\mathrm{a}}$ Maximum dry unit weight; ${ }^{\mathrm{b}}$ Optimum water content. 
presenting a uniform grain size distribution, this aggregate was predominantly composed of concrete.

Table 3 - Effect of loading process on specific gravity of the RCDW aggregates.

\begin{tabular}{lcc}
\hline \multirow{2}{*}{ Sample } & \multicolumn{2}{c}{ Specific gravity $-G_{s}\left(\mathrm{~g} / \mathrm{cm}^{3}\right)$} \\
\cline { 2 - 3 } & Passing $(4.75-\mathrm{mm})$ & Retained $(4.75-\mathrm{mm})$ \\
\hline A-A - No Loading ${ }^{\mathrm{a}}$ & 2.166 & 2.684 \\
A-A - $150 \mathrm{kPa}$ & 2.156 & 2.650 \\
A-A - 300 kPa & 2.117 & 2.664 \\
A-A - $600 \mathrm{kPa}$ & 2.224 & 2.776 \\
A-B - No Loading ${ }^{\text {a }}$ & 2.602 & 2.658 \\
A-B - $150 \mathrm{kPa}$ & 2.660 & 2.645 \\
A-B - 300 kPa & 2.643 & 2.635 \\
A-B - 600 kPa & 2.614 & 2.686 \\
A-C - No Loading ${ }^{a}$ & 2.603 & 2.674 \\
A-C - $150 \mathrm{kPa}$ & 2.600 & 2.658 \\
A-C - 300 kPa & 2.586 & 2.678 \\
A-C - 600 kPa & 2.609 & 2.678 \\
\hline
\end{tabular}

Note: ${ }^{a}$ Mean value of five samples.

\subsection{2. $R C D W$ particle shape and roughness}

Images of the studied materials (A-A, A-B, and A-C) - intact and subjected to the loading process - were taken using a microscope to analyze the effect of loading on particle shape and roughness. The materials retained in sieves 9.5-mm, 4.75-mm, and 2.0-mm were analyzed separately, so their characteristics could be verified in relation to the specific applied load.

The images did not allow to verify any difference related to particle shapes. No relationship between loading process and grain roughness changes was observed in grains retained in sieves $2.00-\mathrm{mm}$ and $4.75-\mathrm{mm}$. This can be justified by the fact that coarser particles are the ones presenting most modification in relation to the shape when subject to loading, as stated by Leite et al. (2011). The image of Aggregate $\mathrm{C}$ particles retained in the sieve $9.5-\mathrm{mm}$ (Fig. 11) revealed a smooth surface for loading of $600 \mathrm{kPa}$. Results revealed that the maximum load of $600 \mathrm{kPa}$, although not enough to break the particle when it consisted of natural aggregate (rock), could remove the mortar around the natural aggregate. This can explain the changes showed when comparing the grain size distribution of materials subject to the loading process. (a)

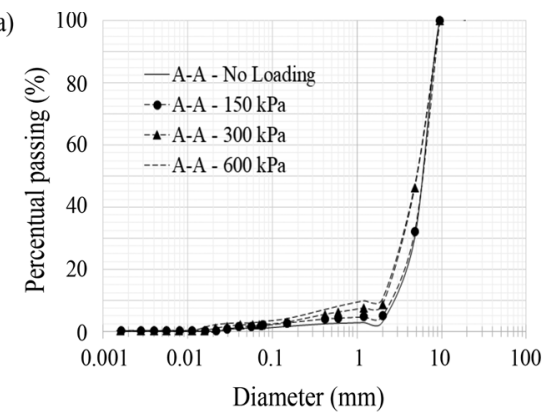

(b)

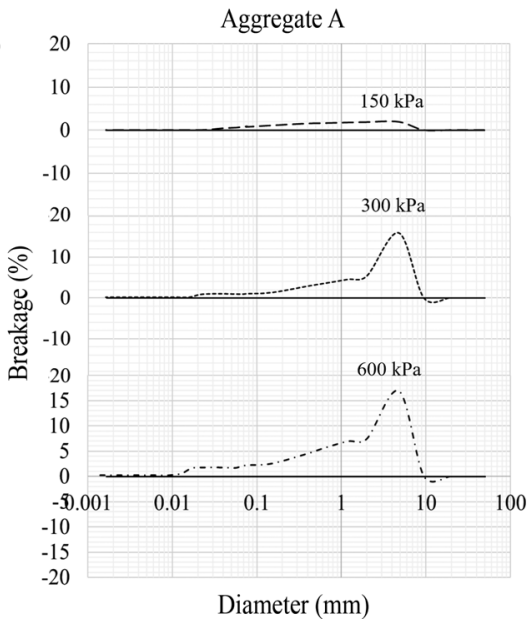

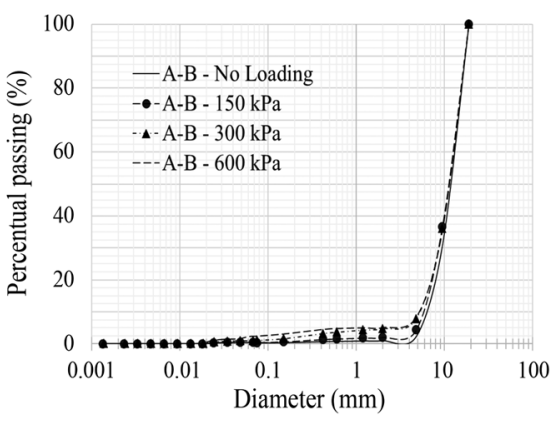
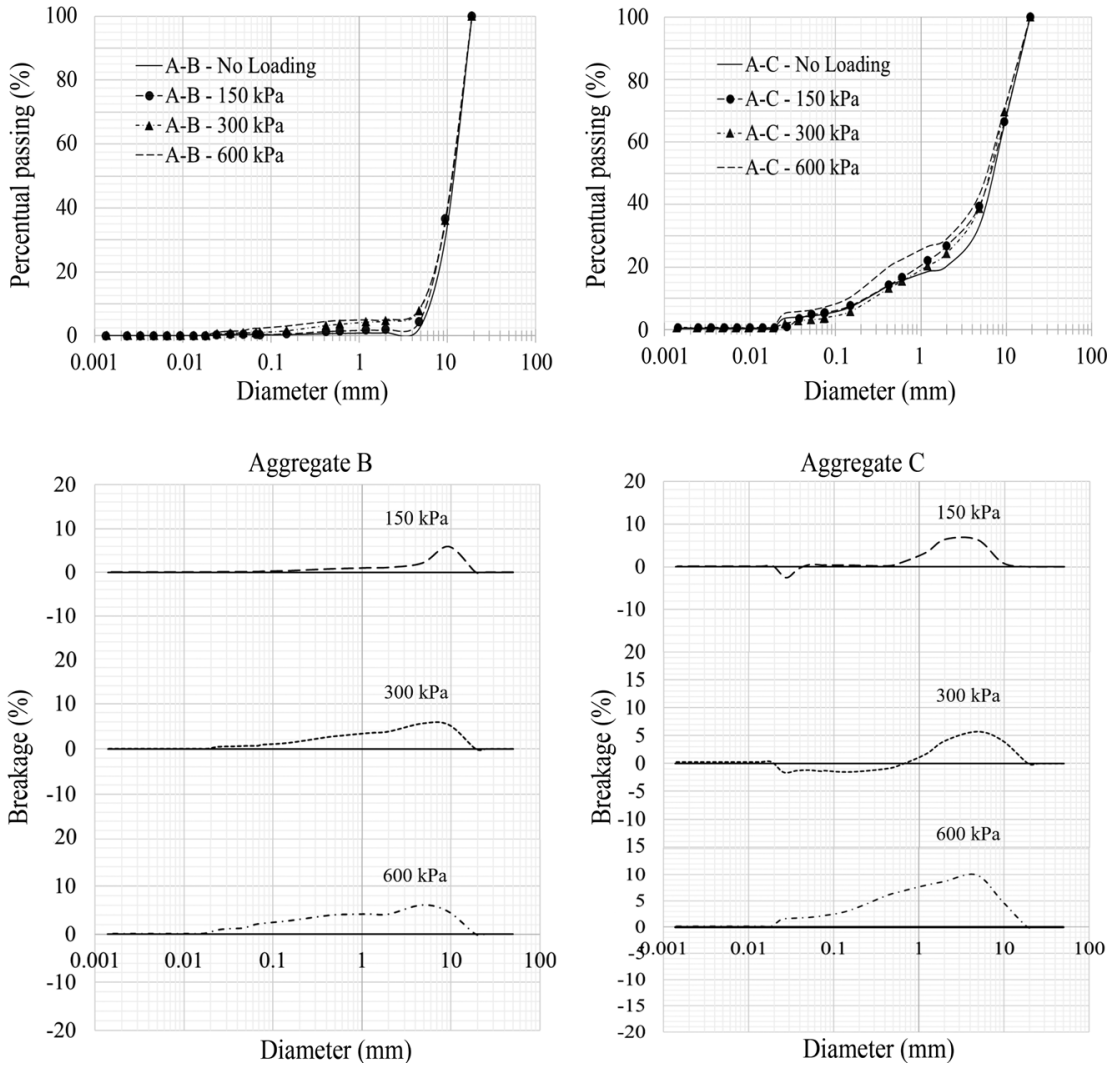

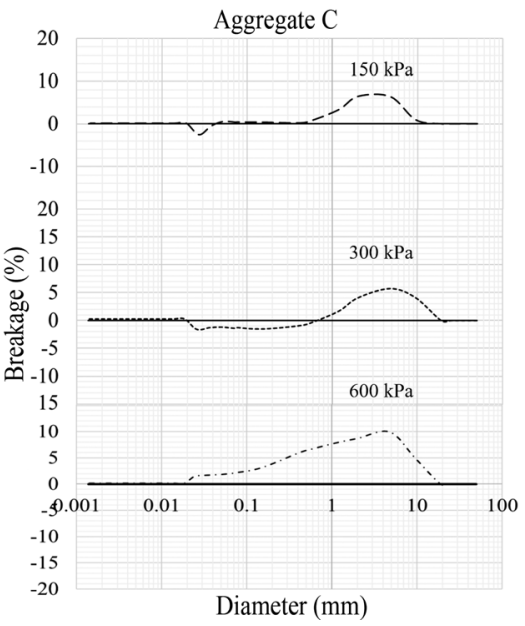

Figure 10 - Granulometric analysis of aggregates for different loads: a) Grain size distribution curves, b) Percentage difference of particle passing. 


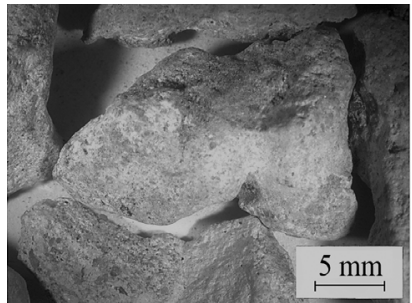

(a)

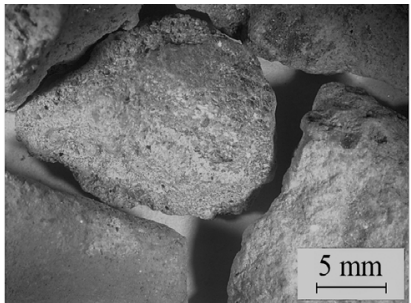

(b)

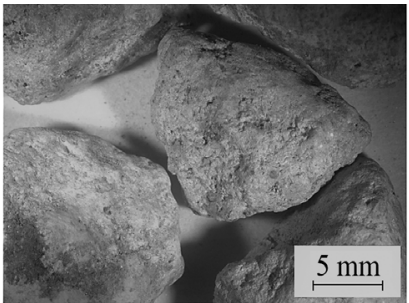

(c)

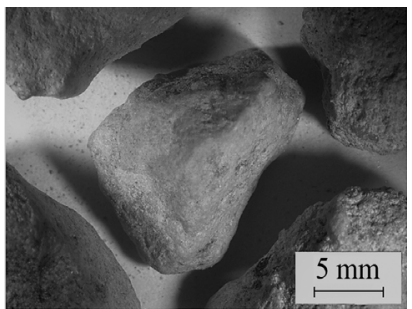

(d)

Figure 11 - Grains of A-C retained sieve 9.5-mm: a) No loading, b) $150 \mathrm{kPa}$, c) $300 \mathrm{kPa}$, d) $600 \mathrm{kPa}$.

\subsection{Geogrids}

\subsubsection{Tensile test in virgin samples and determination of confidence interval}

The results of tensile tests carried out on five virgin samples of each geogrid type revealed smaller ultimate tensile strength $\left(T_{u l}\right)$ compared to the manufacturer's information (see section 2.1.2). GGPVA presented a mean value of $T_{u t t}$ equal to $26.3 \mathrm{kN} / \mathrm{m}$ and the lowest variability $(C O V=7.8 \%)$, meanwhile GGPET01 showed a mean value of $T_{u l t}$ equal to $38.7 \mathrm{kN} / \mathrm{m}$ and the highest variability $(\mathrm{COV}=13.2 \%)$. GGPET02 presented a mean value of $T_{u l t}$ equal to $27.4(\mathrm{COV}=12.2 \%)$.

In relation to the tensile stiffness, the GGPVA showed the lowest variability for stiffness at $2 \%\left(J_{2 \sigma_{o}}\right)$. This geogrid revealed an average $J_{2 \%}$ equal to $550.00 \mathrm{~N} / \mathrm{m}$ and value of $C O V$ equal to $6 \%$. Due to the fact that the tensile rupture occurred below the strain of $5 \%$, the stiffness for this scenario $\left(J_{5 \%}\right)$ was not calculated. The results showed that the GGPET 01 presented mean values of $J_{2 \%}$ and $J_{5 \%}$ equal to $694.00 \mathrm{~N} / \mathrm{m}(\operatorname{COV}=25 \%)$ and $555.20 \mathrm{~N} / \mathrm{m}$
$(\mathrm{COV}=16.2 \%)$, respectively. The GGPET 02 revealed $J_{2 \%}$ equal to $680.00 \mathrm{~N} / \mathrm{m}$ with the highest variability $(C O V=33.4 \%)$ and $J_{5} \%$ equal to $408.80 \mathrm{~N} / \mathrm{m}$ $(C O V=16.6 \%)$.

The virgin samples presented values of strains at rupture $\left(\varepsilon_{\text {rup }}\right)$ below $5 \%$ for the GGPVA, and below $10 \%$ for the polyester geogrids (GGPET 01 and GGPET 02). The virgin samples of GGPVA presented the lowest variability of $\varepsilon_{r u}$, showing value of $C O V$ equal to $5.4 \%$ (mean value of $\varepsilon_{\text {rup }}=4.7 \%$ ), meanwhile GGPET 01 showed the highest variability, with value of $C O V$ equal to $21.7 \%$ (mean value of $\left.\varepsilon_{\text {rup }}=6.6 \%\right)$. GGPET 02 revealed value of $C O V$ equal to $21.5 \%$ (mean value of $\varepsilon_{r u p}=5.8 \%$ ) for virgin samples.

Based on the data obtained from the virgin samples, the confidence intervals for each kind of geogrid were determined by means of the Student's $t$-distribution. Table 4 presents the confidence limits for each of the parameters of interest and their respective confidence levels. It can be observed that the confidence level values were between $96 \%$ and $98 \%$, very similar to the ones found by Barbosa \& Santos (2013) and Santos et al. (2014).

Table 4 - Results from tests on virgin samples (5 specimens) associated with the Student's $t$-distribution analysis.

\begin{tabular}{|c|c|c|c|c|}
\hline Geoogrid & Tensile strength $(\mathrm{kN} / \mathrm{m})$ & Strain at rupture $(\%)$ & $J_{2 \%}(\mathrm{~N} / \mathrm{m})$ & $J_{5 \%}(\mathrm{~N} / \mathrm{m})$ \\
\hline \multirow[t]{4}{*}{ GGPVA } & $\bar{T}_{u l t}=26.3$ & $\bar{\varepsilon}_{r u p}=4.7$ & $\bar{J}_{2 \%}=550.0$ & n.a. \\
\hline & $C O V=7.8 \%$ & $C O V=5.4 \%$ & $C O V=6 \%$ & \\
\hline & $22.55<F_{0}<30.05$ & $4.15<\varepsilon_{r u p}<5.26$ & $488.43<J_{2 \%}<611.57$ & \\
\hline & $C L=98 \%$ & $C L=98 \%$ & $C L=98 \%$ & \\
\hline \multirow[t]{4}{*}{ GGPET 01} & $\bar{T}_{u l t}=38.7$ & $\bar{\varepsilon}_{\text {rup }}=6.6$ & $\bar{J}_{2 \%}=694.0$ & $\bar{J}_{5 \%}=555.2$ \\
\hline & $C O V=13.2 \%$ & $C O V=21.7 \%$ & $C O V=25 \%$ & $C O V=16.2 \%$ \\
\hline & $31.05<F_{0}<46.35$ & $3.98<\varepsilon_{r u p}<9.22$ & $434.13<J_{2 \%}<953.87$ & $420.26<J_{5 \%}<690.14$ \\
\hline & $C L=96 \%$ & $C L=98 \%$ & $C L=96 \%$ & $C L=96 \%$ \\
\hline \multirow[t]{4}{*}{ GGPET 02} & $\bar{T}_{u l t}=27.4$ & $\bar{\varepsilon}_{r u p}=5.8$ & $\bar{J}_{2 \%}=680.0$ & $\bar{J}_{5 \%}=408.8$ \\
\hline & $C O V=12.2 \%$ & $C O V=21.5 \%$ & $C O V=33.4 \%$ & $C O V=16.6 \%$ \\
\hline & $22.45<F_{0}<32.35$ & $3.55<\varepsilon_{\text {rup }}<8.05$ & $254.42<J_{2 \%}<1105.58$ & $307.07<J_{5 \%}<510.53$ \\
\hline & $C L=96 \%$ & $C L=98 \%$ & $C L=98 \%$ & $C L=96 \%$ \\
\hline
\end{tabular}

Note: $T_{u l t}=$ ultimate tensile strength; $\varepsilon_{r u p}=$ strain at rupture; $J_{2 \%}=$ stiffness at $2 \%$ strain; $J_{5 \%}=$ stiffness at $5 \%$ strain; $C L=$ confidence level; n.a. = not available. 


\subsubsection{Geogrids' tensile strength, strain at rupture and} secant tensile stiffness after loading

\subsubsection{GGPVA}

Considering all the scenarios, it was observed that GGPVA did not present the mean value of ultimate tensile strength $\bar{T}_{u l t}$ outside the limits calculated for this parameter. However, the strain at rupture $\left(\varepsilon_{r u p}\right)$ appeared as a sensitive parameter to the loading process, which can be verified evaluating the reduction of $T_{u l t}$ values and the increase of $C O V$. Figure 12a shows the strength values obtained while testing the GGPVA with each kind of RCDW.

Aggregate C - classified as a poorly graded gravel with silt - caused the higher reduction factor of average $\varepsilon_{\text {rup }}$ when the GGPVA was submitted to the load of $150 \mathrm{kPa}$, which confirms that the responses of this parameter were not affected in a direct relation to loading (Fig. 12b). However, it was possible to see that other load magnitudes caused reductions of this parameter close to the lower limit established by statistical analysis. It is also possible to visualize the increase of $C O V$ when strain at rupture of virgin and exhumed specimens are compared.

Results revealed that Aggregate B - classified as poorly graded gravel - caused the greatest reduction of $\varepsilon_{r u p}$ and the highest variability when tested with a load of $300 \mathrm{kPa}$ if compared to the other loads applied for that same material (Fig. 12b). Evaluating the results from tests with Aggregate A - classified as poorly graded gravel -, it is possible to observe that a load of $600 \mathrm{kPa}$ caused the highest reduction of $\varepsilon_{r u p}$, but this reduction was not directly related to load (Fig. 12b). These results show the need for a better separa-

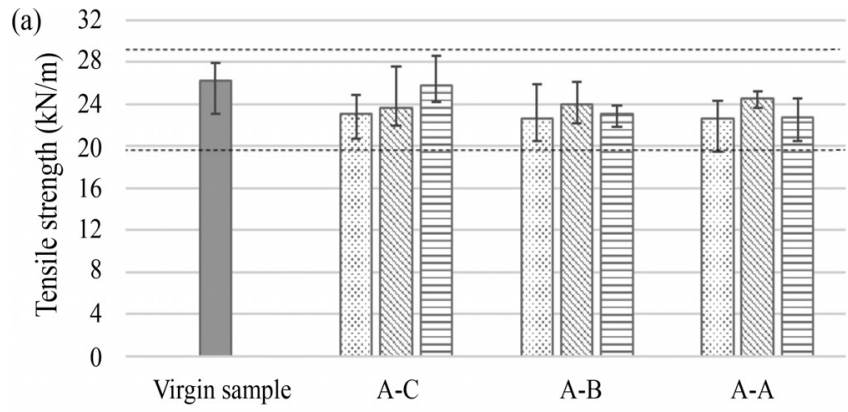

(c)

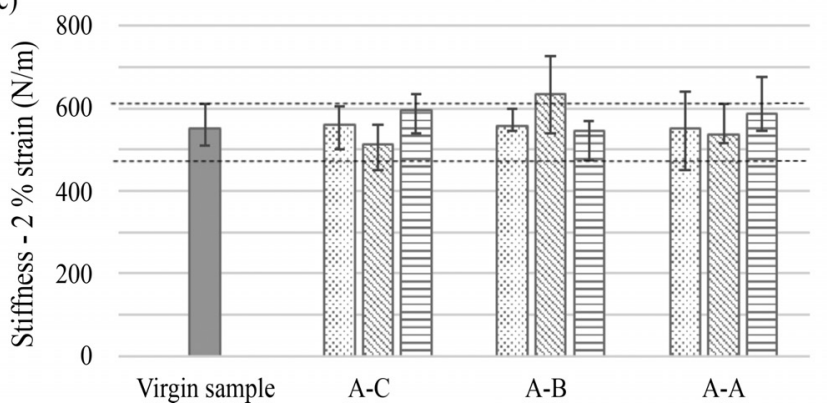

tion of the materials that compose the RCDW, once the existence of components that could be broken easily (e.g. ceramic materials) can cause different damages in the geogrid tested.

In general, the analyses of stiffness at $2 \%\left(\mathrm{~J}_{2} \%_{\%}\right)$ showed that different scenarios (recycled aggregate $v s$. load) have not changed the mean values of this parameter, with most of the values ranging within the limits of virgin specimens - except for scenario Aggregate B submitted to $300 \mathrm{kPa}$ (Fig. 12c). As pointed out during the discussion of the values of $T_{u l t}$, the results revealed an increase of the $\mathrm{COV}$ of exhumed samples.

\subsubsection{GGPET 01}

The evaluation of all scenarios revealed that GGPET 01 did not present average ultimate tensile strength $\left(\bar{T}_{u l t}\right)$ outside the limits calculated for this parameter using the virgin specimen data and the Student's $t$-distribution. The mean values of $\varepsilon_{r u p}, J_{2 \%}$, and $J_{5 \%}$ were also within the limits calculated, however, for these parameters, some specimens presented values beyond the limits. Figures 13a to $13 \mathrm{~d}$ show the results of each investigated parameter.

GGPET 01 presented the value of strain at rupture, for the sample Aggregate B and load of $300 \mathrm{kPa}$, with a $C O \mathrm{~V}$ value of $13 \%$ (Fig. 13b). The high variation of GGPET 01 samples was beyond the upper limit of the confidence inter$\mathrm{val}$, and this performance could be a limitation for its use in some geotechnical works.

\subsubsection{GGPET 02}

Considering the different scenarios analyzed, it was noticed that GGPET 02 did not present average ultimate

(b) 6

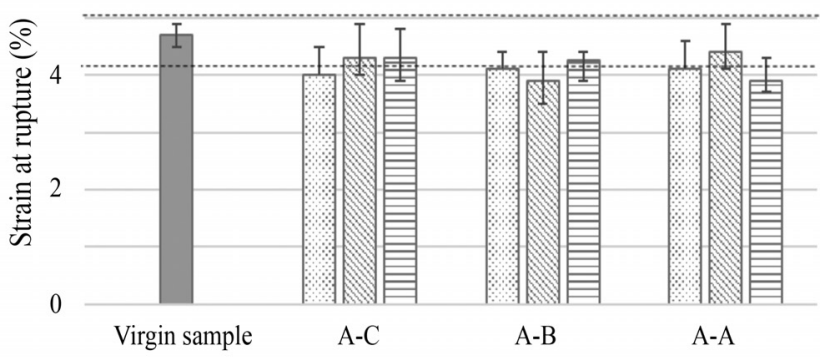

GGPVA

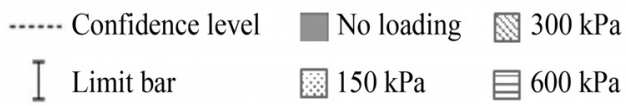

Figure 12 - GGPVA: a) Tensile strength; b) Rupture Strain; c) Stiffness - $2 \%$ Strain. 


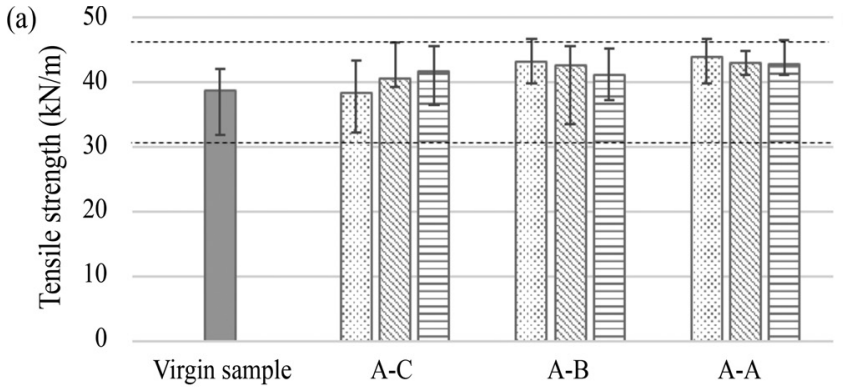

(c)

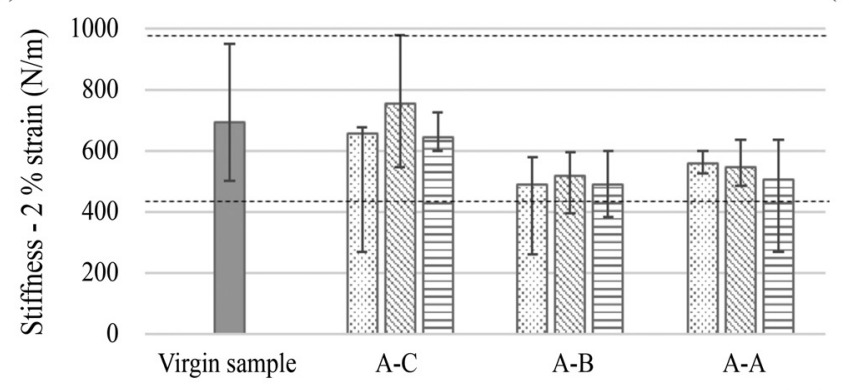

(b)

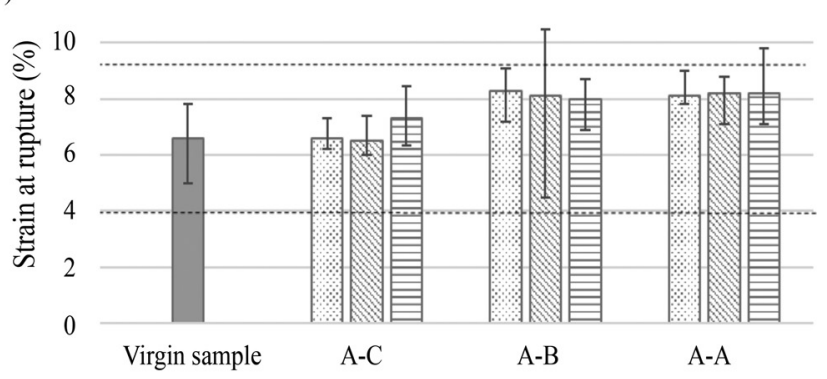

(d)

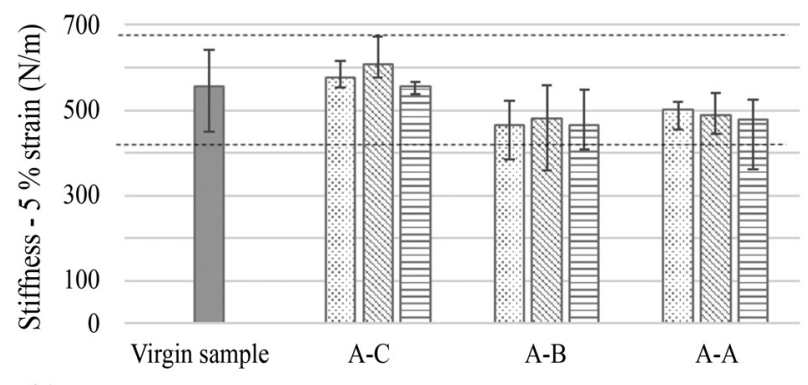

GGPET 01

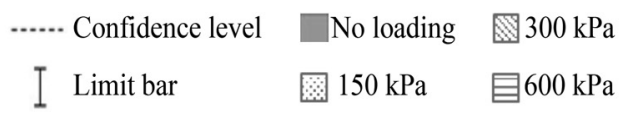

Figure 13 - GGPET 01: a) Tensile strength; b) Rupture Strain; c) Stiffness - $2 \%$ Strain; and d) Stiffness - $5 \%$ Strain.

tensile strength $\left(\bar{T}_{u t}\right)$ values outside the calculated limits (Fig. 14a). However, the Aggregate B sample (300 kPa) stands out due to the greater variation of the deformation at rupture $\left(\varepsilon_{\text {rup }}\right)$ (Fig. 14b).

Aggregate $\mathrm{C}$ caused the higher reduction factor of average deformation at rupture $\left(\bar{\varepsilon}_{\text {rup }}\right)$ when GGPET 02 was submitted to the load of $150 \mathrm{kPa}$ (Fig. 14b), which proves that the responses of this parameter were not affected in a direct relation to load - as well as GGPVA. Results revealed that Aggregate B caused an increase of $\varepsilon_{r u p}$ for all applied loads (Fig. 14b), with the load of $600 \mathrm{kPa}$ being the most expressive one. For Aggregate A, it is possible to observe that a load of $600 \mathrm{kPa}$ caused a higher increase of $\varepsilon_{r u p}$, and this reduction was not directly related to load (Fig. 14b).

In general, the analyses of stiffness at $2 \%\left(J_{2}\right)$ showed that the virgin sample presented a high value of COV (33.4\%). Besides that, all tested geogrids presented values smaller than the virgin sample (Fig. 14c). The Aggregate $\mathrm{C}$ and Aggregate $\mathrm{A}$ showed values within the confidence level. Only Aggregate B presented a reduction of $J_{2 \%}$ for loads of $300 \mathrm{kPa}$ and $600 \mathrm{kPa}$ (Fig. 14c). For this aggregate, the results revealed an increase of the $C O V$ of damaged samples in comparison to the one of virgin ones (e.g. scenario of $300 \mathrm{kPa}$ presented a $\mathrm{COV}=98.4 \%$ ).

Considering the mean values of stiffness at $5 \%\left(J_{5 \%}\right)$ (Fig. 14d), for all loads, Aggregate A and Aggregate C did not cause any reduction beyond the limits. Aggregate B caused some reduction in the $J_{5 \%}$ proportional to the applied load, with the largest reduction of this parameter being observed for the load of $600 \mathrm{kPa}$. Although Aggregate A and Aggregate $\mathrm{C}$ did not cause any reduction factor $\left(J_{5 \%}\right)$ in tested samples, these aggregates did present average values lower than virgin samples. Thus, the results revealed that the fact of Aggregate B being the coarser material can be pointed out as the reason why the greatest damages were observed in geogrids when using this material.

\subsubsection{Reduction factors due to loading process}

The results showed that the reduction factor $(R F)$ presented diverse magnitudes for each parameter and scenario. Considering the different scenarios evaluated (aggregates $v s$. loads), it was noticed that all tested geogrids (PVA or PET), irrespective of their catalogue tensile strength $(35 \mathrm{kN} / \mathrm{m}$ or $55 \mathrm{kN} / \mathrm{m}$ ), did not present average ultimate tensile strength values $\left(\bar{T}_{u l t}\right)$ outside the calculated limits (confidence intervals). For other parameters, only the cases with $35 \mathrm{kN} / \mathrm{m}$ geogrids (GGPVA and GGPET 02) presented values of RF other than 1.0. In terms of reduction factors related to deformation at failure $\left(R F \varepsilon_{\text {rup }}\right)$, the PVA geogrid showed values ranging from 1.15 to 1.21 (Table 5), hence becoming the most sensitive geogrid to the loading process. Aggregate A - classified as a poorly graded gravel with sand - presented moderate damages; while Aggregate B - classified as poorly graded gravel - contributed to a higher occurrence of damages. Aggregate C - classified as 

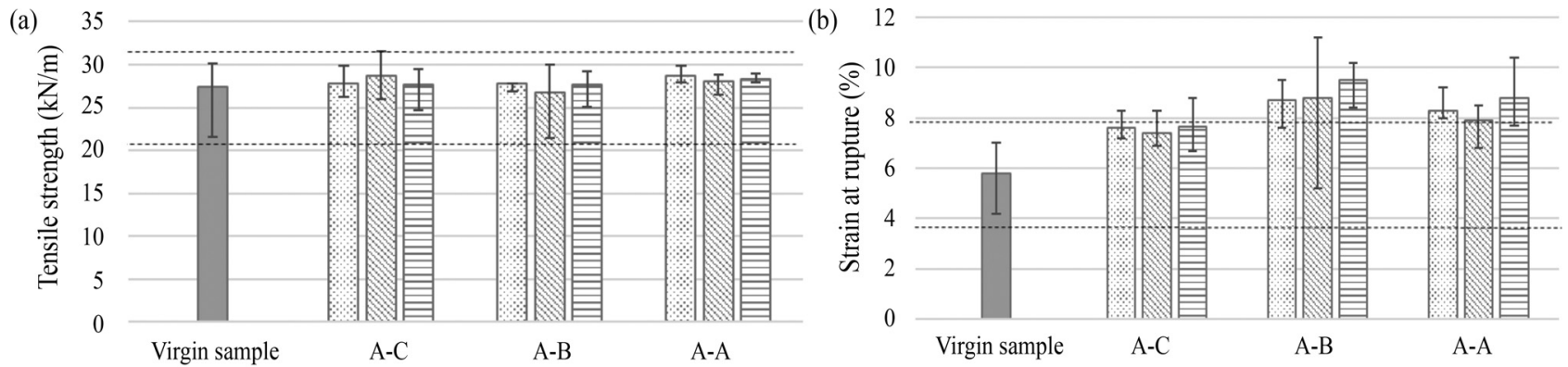

(c)

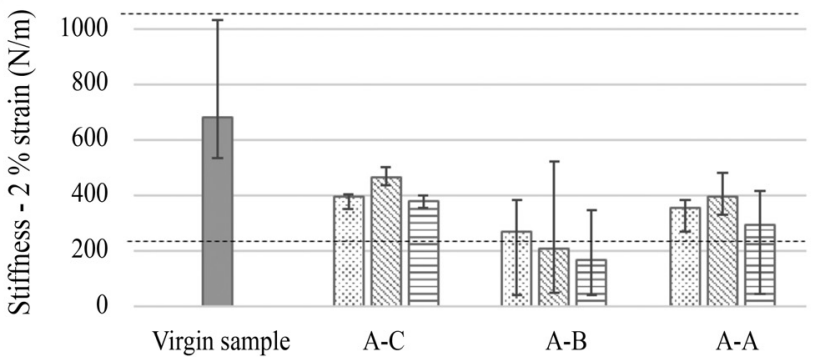

(d)

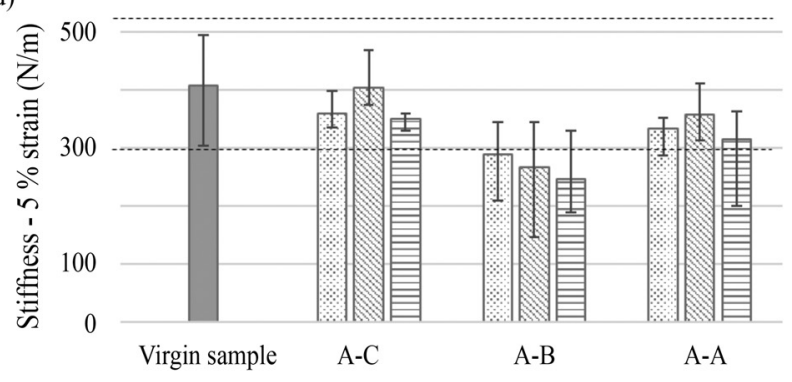

GGPET 02

$\begin{array}{lll}\text { ….. Confidence level } & \text { No loading } 300 \mathrm{kPa} \\ \text { I Limit bar } & 150 \mathrm{kPa} & \text { 目 } 600 \mathrm{kPa}\end{array}$

Figure 14 - GGPET 02: a) Tensile strength; b) Rupture Strain; c) Stiffness - $2 \%$ Strain; and d) Stiffness - $5 \%$ Strain.

poorly graded silty gravel with sand - was the least aggressive material.

Concerning the reduction factors related to stiffness at $2 \%\left(R F_{52 \%}\right)$, the PET geogrid $(35 \mathrm{kN} / \mathrm{m})$ presented values from 3.29 to 4.12 (Table 5), when tested with Aggregate B, for loads of $300 \mathrm{kPa}$ and $400 \mathrm{kPa}$, respectively. However, as reported by Fleury et al. (2019), it is worth mentioning that the method of monitoring the strain during the tensile strength test (in only one longitudinal rib) may have been the reason for the wide range of secant tensile stiffness values obtained. Therefore, once virgin samples presented excessively broad confidence intervals, it is reasonable to have a high occurrence of reduction factors equal to 1.00. Moreover, whenever different values are observed, overstated magnitudes become evident. The results have also shown that the difficulty of obtaining reduction factors increases when concerning $R F_{J 2}$.

The values of reduction factor related to tensile stiffness at $5 \%\left(R F_{J 5}\right)$ varied from 1.41 to 1.66 for PET geogrid (35 kN/m) (Table 5), when tested with Aggregate B. Although the values of $R F_{55}$ had shown a direct relation to load, one must bear in mind that this case was not observed in most of the scenarios investigated. Unlike what was perceived in the values of stiffness at $2 \%\left(J_{2 \%}\right)$, those of stiffness at $5 \%\left(J_{5} \%\right)$ did not present a high variability (COV up to $16.6 \%$ ). Therefore, $R F_{J 5}$ seems very reasonable.
Given that the majority of scenarios presenting values of $R F$ greater than 1.00 were related to tests carried out with Aggregate B, it is possible to state that the characteristics of this material, correlated to $\mathrm{i}$ ) the predominance of coarse particles (gravel, $D_{85}=18 \mathrm{~mm}, D_{50}=11 \mathrm{~mm}, D_{10}=6.5 \mathrm{~mm}$ ), ii) poorly graded grain size distribution $\left(C_{U}=1.85\right)$, and iii) lower particle breakage occurrence, contributed to damage generation and its degree of severity. These characteristics create a condition with few points of contact between the aggregate (particles) and geogrid elements, causing a concentration of load and, as a consequence, more severe damages.

On the other hand, despite also presenting coarse particles (gravel with silt, $D_{85}=12 \mathrm{~mm}, D_{50}=7.5 \mathrm{~mm}, D_{10}=$ $0.22 \mathrm{~mm}$ ), Aggregate $\mathrm{C}$, due to the content of coarse, medium and fine sands (total amount around $26 \%$ ), the considerable value of coefficient of uniformity $\left(C_{U}=38.64\right)$ and high particle breakage, was able to provide a condition of large particles surrounded by small ones, setting up better load transfer (large contact area) between its particles and the geogrids. This condition made Aggregate C (material produced from a mixture of three recycled materials) the least aggressive material, presenting only one scenario with RF greater than 1.0 (GGPAV, $150 \mathrm{kPa}, R F \varepsilon_{\text {rup }}=1.18$ ). Moreover, this aggregate is the cheapest material produced by the recycling plant. Table 5 summarizes all the reduction factors obtained by the tensile test. 
Table 5 - Reduction factors related to the investigated parameters.

\begin{tabular}{|c|c|c|c|c|c|c|}
\hline \multirow[t]{2}{*}{ Aggregate } & \multicolumn{2}{|c|}{$R F \varepsilon_{r u p}{ }^{a}$} & \multicolumn{2}{|c|}{$R F_{J 2 \%}^{\mathrm{b}}$} & \multicolumn{2}{|c|}{$R F_{J 5 \%}{ }^{\mathrm{c}}$} \\
\hline & GGPVA & GGPET 02 & GGPVA & GGPET 02 & GGPVA & GGPET 02 \\
\hline \multirow{3}{*}{ A-C } & $1.18(150)$ & $1.00(150)$ & $1.00(150)$ & $1.00(150)$ & - & $1.00(150)$ \\
\hline & $1.00(300)$ & $1.00(300)$ & $1.00(300)$ & $1.00(300)$ & - & $1.00(300)$ \\
\hline & $1.00(600)$ & $1.00(600)$ & $1.00(600)$ & $1.00(600)$ & - & $1.00(600)$ \\
\hline \multirow{3}{*}{ A-B } & $1.15(150)$ & $0.67^{\mathrm{d}}(150)$ & $1.00(150)$ & $1.00(150)$ & - & $1.41(150)$ \\
\hline & $1.21(300)$ & $0.66^{\mathrm{d}}(300)$ & $0.87^{\mathrm{d}}(300)$ & $3.29(300)$ & - & $1.53(300)$ \\
\hline & $1.00(600)$ & $0.61^{\mathrm{d}}(600)$ & $1.00(600)$ & $4.12(600)$ & - & $1.66(600)$ \\
\hline \multirow{3}{*}{ A-A } & $1.15(150)$ & $0.70^{\mathrm{d}}(150)$ & $1.00(150)$ & $1.00(150)$ & - & $1.00(150)$ \\
\hline & $1.00(300)$ & $1.00(300)$ & $1.00(300)$ & $1.00(300)$ & - & $1.00(300)$ \\
\hline & $1.21(600)$ & $0.66^{\mathrm{d}}(600)$ & $1.00(600)$ & $1.00(600)$ & - & $1.00(600)$ \\
\hline
\end{tabular}

Note: ${ }^{\mathrm{a}}$ Reduction factor related to the strain at failure; ${ }^{\mathrm{b}}$ Reduction factor related to the secant tensile stiffness at $2 \%$; ${ }^{\mathrm{R}}$ Reduction factor related to the secant tensile stiffness at $5 \%$; ${ }^{\mathrm{d}}$ The adoption of reduction factor equal to 1.0 is recommended. Loads are presented between parentheses in $\mathrm{kPa}$.

\section{Conclusions}

This paper reported on mechanical damage caused to geogrids by recycled construction and demolition wastes (RCDW) with different grain size distributions. Laboratory tests were carried out to apply loads simulating the field condition to the composite (geogrid + RCDW). Tensile tests were performed on damaged geogrid specimens, and the RCDW grain size distribution was evaluated before and after the loading application. The main conclusions obtained are presented below.

(1) The geotechnical characterization revealed that the RCDW presented non-plastic and non-liquid behavior. Besides, according to USCS, these materials presented grain size distributions from clean gravel to gravel with few fines. The mean value of dry unit weight was equal to $16.859 \mathrm{kN} / \mathrm{m}^{3}$ and mean optimum water content was equal to $17.6 \%$, which showed that the content of ceramic materials is directly proportional to the optimum water content.

(2) The grain size distribution curves of RCDW presented significant changes when subjected to different loading. No abrupt breakage of recycled aggregates subjected to loading was noticed, except for the removal of fines around the particles with loading. Thus, after application of the load, the material presented a smooth surface (less rough).

(3) The analysis of grain roughness revealed that the particles larger than $9.5 \mathrm{~mm}$ were the ones most affected with the application of the load. The grain breakage can influence the mechanical and hydraulic properties of the materials.

(4) The test simulating mechanical damage in geogrids revealed that: i) although the results presented some values of tensile strength outside the limits calculated based on virgin specimens, the mean values for all in- vestigated scenarios were within the minimum and maximum limits; ii) the reduction factors related to the strain at rupture wound up being greater than those obtained for other analyzed parameters; iv) the GGPVA and GGPET 02 geogrids presented higher reduction factors related to strain at rupture and stiffness.

(5) The damage caused by Aggregate B turned out to be more severe, given that this aggregate was the coarser one, presenting a poorly graded grain size distribution and revealing the lowest particle size variation (breakage) due to loading process. The aggregate mostly produced and sold by the recycling plant (Aggregate $\mathrm{C}$ ), with the lowest selling price, was also the least aggressive material.

(6) The values of RF calculated revealed the need for proper investigation when using RCDW as backfill material, which could enable them in the design phase. The authors believe the results presented may contribute to a better understanding of the processes involved in mechanical damage of polymeric reinforced elements, and to the goal of achieving positive economic, social and environmental benefits related to the use of recycled materials in geotechnical works.

\section{Acknowledgments}

The authors are indebted to the following institutions that supported the research activities reported in this paper in different ways: Federal University of Goiás (UFG), National Council for Scientific and Technological Development (CNPq), University of São Paulo (USP), and CAPES - Brazilian Ministry of Education. The authors also thank the manufacturer of geosynthetics and RNV - Waste Management, for providing information and materials presented in this paper. 


\section{References}

ABNT (2016a). Gravel Grains Retained on the $4.8 \mathrm{~mm}$ Mesh Sieve - Determination of the Bulk Specific Gravity, of the Apparent Specific Gravity and of Water Absorption - NBR 6458:2016. The Brazilian Association of Technical Standards, Rio de Janeiro, RJ, Brazil, 10 p. (In Portuguese).

ABNT (2016b). Soil - Granulometric Size Analysis - NBR 7181:2016. The Brazilian Association of Technical Standards, Rio de Janeiro, RJ, Brazil, 12 p. (In Portuguese).

ABNT (2016c). Soil - Liquid Limit Determination - NBR 6459:2016. The Brazilian Association of Technical Standards, Rio de Janeiro, RJ, Brazil, 5 p. (In Portuguese).

ABNT (2016d). Soil - Plasticity Limit Determination NBR 7180:2016. The Brazilian Association of Technical Standards, Rio de Janeiro, RJ, Brazil, 3 p. (In Portuguese).

ABNT (2016e). Soil - Compaction Test - NBR 7182:2016. The Brazilian Association of Technical Standards, Rio de Janeiro, RJ, Brazil, 1 p. (In Portuguese).

Afshar, T.; Disfani, M.M.; Arulrajah, A.; Narsilio, G. A. \& Eman, S. (2017). Impact of particle shape on breakage of recycled construction and demolition aggregates. Powder Technology, 308:1-12. https://dx.doi.org/10.1016/j.powtec.2016.11.043.

Allen, T.M. \& Bathurst, R.J. (1994). Characterization of geosynthetic load-strain behavior after installation damage. Geosynthetic International, 1(2):181-199. https://doi.org/10.1680/gein.1.0008.

Allen, T.M. \& Bathurst, R.J. (1996). Combined allowable strength reduction factor for geosynthetic creep and installation damage. Geosynthetic International, 3(3):407-439.

Angulo, S.C.; Teixeira, C.E. \& Castro, A.L. (2011). Construction and demolition waste: evaluation of quantification methods. Engenharia Sanitária e Ambiental, 16(3):299-306. https://doi.org/10.1590/S1413-41522011000300013.

ASTM (2017). Standard Practice for Classification of Soils for Engineering Purposes (Unified Soil Classification System) - D2487-17e1. ASTM International, West Conshohocken, Pennsylvania, USA, 10 p.

ASTM (2015). Standard Test Method for Determining Tensile Properties of Geogrids by the Single or MultiRib Tensile Method - D6637 / D6637M-15. ASTM International, West Conshohocken, Pennsylvania, USA, $6 \mathrm{p}$.

Barbosa, K.R.M. (2017). Geogrid Degradation in Unpaved Roads Built with Recycled Construction and Demolition Wastes (RCDW). M.Sc. Thesis. Graduate Programme of Civil Engineering, University of Pernambuco, Recife, 122 p.
Barbosa, F.A.S. \& Santos, E.C.G. (2013). Geogrid mechanical damages due to recycled construction and demolition wastes. Proc. 14th International Waste Management and Landfill Symposium, Santa Margherita di Pula, Italy, v. 1, pp. 1-8. (CD-ROM)

BSI (2007). Geosynthetics. Index test procedure for evaluation of mechanical damage under repeated loading. Damage Caused by Granular Material - EN ISO 10722:2007. British Standard Institution, London, United Kingdom, 12 p.

BSI (2010). Code of Practice for Strengthened/Reinforced Soils and Other Fills - 8006-1. British Standard Institution, London, United Kingdom, 260 p.

Cardoso, R.; Silva, R.V.; Brito, J. \& Dhir, R. (2016). Use of recycled aggregates from construction and demolition waste in geotechnical applications: A literature review. Waste Management, 49:131-145. https://doi.org/10.1016/j.wasman.2015.12.021.

Esin, T. \& Cosgun, N. (2007). A study conducted to reduce construction waste generation in Turkey. Building and Environment, 42(4):1667-1674. https://doi.org/10.1016/j.buildenv.2006.02.008.

Fleury, M.P. (2018). Geogrid Strength after Mechanical Damages Caused by Recycled Construction and Demolition Wastes (RCDW). MSc. Thesis. Graduate Programme of Geotechnics, Structural and Civil Engineering, Federal University of Goiás, Goiânia, 160 p. (In Portuguese).

Fleury, M.P.; Santos, E.C.G.; Lins da Silva, J.; Palmeira, E.M. (2019). Geogrid installation damage caused by recycled construction and demolition waste. Geosynthetics International, 26(6):641-656. https://doi.org/10.1680/jgein.19.00050.

Gonzalez-Torre, I.; Calzada-Perez, M.A.; Vega-Zamanillo, A. \& Castro-Fresno, D. (2014). Damage evaluation during installation of geosynthetics used in asphalt pavements. Geosynthetics International, 21(6):377-386.

Herrador, R.; Perez, P.; Garach L. \& Ordonez J. (2012). Use of recycled construction and demolition waste aggregate for road course surfacing. Journal of Transportation Engineering, 138(2):182-190. DOI: 10.1061/(ASCE)TE.1943-5436.0000320.

Huang, C.C. (2006). Laboratory simulation of installation damage of a geogrid. Geosynthetics International, 13(3):120-132.

Huang, C.C. \& Chiou, S.L. (2006). Investigation of installation damage of some geogrids using laboratory tests. Geosynthetics International, 13(1):23-35.

Huang, C.C. \& Wang, Z.N. (2007). Installation damage of geogrids: influence of load intensity. Geosynthetics International, 14(2):65-75.

Jones, C.J.F.P. (1994). Economic construction of reinforced soil structures. Proc. International Symposium on Recent Case Histories of Permanent Geosynthetic- 
Reinforced Soil Retaining Walls, Tokyo. Balkema, Kalamazoo, pp. 103-106.

Kartam, N.; Al-Mutairi, N.; Al-Ghusain, I. \& Al-Humoud, J. (2004). Environmental management of construction and demolition waste in Kuwait. Waste Management, 24(10):1049-1059.

https://doi.org/10.1016/j.wasman.2004.06.003.

Leite, F.C.; Motta, R.S.; Vasconcelos, K.L. \& Bernucci, L. (2011). Laboratory evaluation of recycled construction and demolition waste for pavements. Construction and Building Materials, 25(6):2972-2979. https://doi.org/10.1016/j.conbuildmat.2010.11.105.

Mascarenha, M.M.A.; Cordão Neto, M.P.; Matos, T.H.C.; Chagas, J.V.R. \& Rezende, L.R. (2018). Effects of the addition of dihydrate phosphogypsum on the characterization and mechanical behavior of lateritic clay. Soils and Rocks, 41(2):157-170. https://doi.org/10.28927/SR.412157.

Ossa A.; Garciá J.L. \& Botero E. (2016). Use of recycled construction and demolition waste (CDW) aggregates: A sustainable alternative for pavement construction industry. Journal of Cleaner Production, 135:379-386. https://doi.org/10.1016/j.jclepro.2016.06.088.

Paula, A.M.; Pinho-Lopes, M. \& Lopes, M.L. (2004). Damage during installation laboratory test. Influence of the type of granular material. Proc. $3^{\text {rd }}$ European Geosynthetics Conference, EUROGEO, Munich, Germany, pp. 603-606.

Pinho-Lopes, M. \& Lopes, M.L. (2014). Tensile properties of geosynthetics after installation damage. Environmental Geotechnics, 1(3):161-178.

Rosete, A.; Lopes, P.M.; Pinho-Lopes, M. \& Lopes, M.L. (2013). Tensile and hydraulic properties of geosynthetics after mechanical damage and abrasion laboratory tests. Geosynthetics International, 20(5):358-374.

Santos E.C.G. (2007). Application of Recycled Construction and Demolition Waste (RCDW) in Reinforced Soil Structures. M.Sc. Thesis. Department of Geotechnics, University of São Paulo, São Carlos, 168 p. (In Portuguese).

Santos, E.C.G. (2011). Experimental Evaluation of Reinforced Walls Built with Recycled Construction and Demolition Waste (RCDW) and Fine Soil. Ph.D. Thesis, Department of Civil and Environmental Engineering, University of Brasília, Brasília, 216 p. (In Portuguese).

Santos, E.C.G.; Bueno, B.S. \& Palmeira, E.M. (2012). Strength reduction of geosynthetics used in RSW built with RCDW as backfill material. Proc. $5^{\text {th }}$ European Geosynthetics Congress, EUROGEO, Valencia, Spain, pp. 481-485.

Santos E.C.G.; Palmeira E.M. \& Bathurst, R.J. (2013). Behaviour of a geogrid reinforced wall built with recycled construction and demolition waste backfill on a collapsible foundation. Geotextiles and Geomembranes,
39(1):9-19.

https://doi.org/10.1016/j.geotexmem.2013.07.002.

Santos, E.C.G.; Palmeira E.M. \& Bathurst, R.J. (2014). Performance of two geosynthetic reinforced walls with recycled construction waste backfill and constructed on collapsible ground. Geosynthetic International, 21(4):256-269. https://doi.org/10.1680/gein.14.00013.

Santos, A.A.M. \& Leite, M.B. (2018). Evaluation of recycled concrete with concrete coarse aggregate using ABCP mix design method modified. Ambiente Construído, 18(4):341-359. http://dx.doi.org/10.1590/s1678-86212018000400309 (In Portuguese).

Silva, R.V.; Brito, J. \& Dhir, R.K. (2016). Availability and processing of recycled aggregates within the construction and demolition supply chain: A review. Journal of Cleaner Production, 143:598-614. https://doi.org/10.1016/j.jclepro.2016.12.070.

Silva, M.V.; Rezende, L.R.; Mascarenha, M.M.A. \& Oliveira, R.B. (2019). Phosphogypsum, tropical soil and cement mixtures for asphalt pavements under wet and dry environmental conditions. Resources, Conservation \& Recycling, 144:123-136. https://doi.org/10.1016/j.resconrec.2019.01.029.

Silvestre, G.R. (2019). Geogrid Strength Reduction due to Chemical Damages Caused by Recycled Construction and Demolition Wastes. M.Sc. Thesis. Graduate Programme of Geotechnics, Structural and Civil Engineering, University of Goiás, Goiânia, 146 p. (In Portuguese).

Tam, V.W.Y. (2008). Economic comparison of concrete recycling: a case study approach. Resource, Conservation and Recycling, 52(5):821-828. https://doi.org/10.1016/j.resconrec.2007.12.001.

Yoo, H.; Jeon, H.Y. \& Chang, Y.C. (2009). Evaluation of engineering properties of geogrids for soil retaining walls. Textile Research Journal, 80(2):184-192.

Wu H.; Zuo J.; Zillante G.; Wang J. \& Yuan H. (2019). Status quo and future directions of construction and demolition waste research: A critical review. Journal of Cleaner Production, 240:1-13. https://doi.org/10.1016/j.clepro.2019.118163.

\section{List of Symbols and Abbreviations}

ABNT: Brazilian Association of Technical Standards

ASTM: American Society for Testing and Materials

A-A: aggregate $\mathrm{A}(9.5 \mathrm{~mm}>d>4.8 \mathrm{~mm})$

$\mathrm{A}-\mathrm{B}$ : aggregate $\mathrm{B}(19 \mathrm{~mm}>d>9.5 \mathrm{~mm})$

A-C: aggregate $\mathrm{C}(d<9.5 \mathrm{~mm})$

CDW: Construction and Demolition Waste

$C L$ : confidence level (dimensionless)

$C_{U}$ : soil coefficient of uniformity $\left(C_{U}=D_{60} / D_{10}\right)$

$d$ : diameter of the particle $(\mathrm{m})$

$D_{10}$ : diameter of the particle for which $10 \%$ of soil in mass

is smaller (than that diameter) 
$D_{50}$ : diameter of the particle for which $50 \%$ of soil in mass is smaller (than that diameter)

$D_{85}$ : diameter of the particle for which $85 \%$ of soil in mass is smaller (than that diameter)

EECA-UFG: School of Civil and Environmental Engineering of the Federal University of Goiás

EESC-USP: School of Engineering of São Carlos, University of São Paulo

$F_{0}$ : tensile strength of virgin samples

GRS: Geosynthetic Reinforced Soil

$G_{s}$ : specific gravity $\left(\mathrm{g} / \mathrm{cm}^{3}\right)$

GGPVA: polyvinyl alcohol geogrid

GGPET 01: polyester geogrid with resistance of $55 \mathrm{kN} / \mathrm{m}$

GGPET 02: polyester geogrid with resistance of $35 \mathrm{kN} / \mathrm{m}$ $J_{\text {sec }}:$ secant tensile stiffness

$J_{2 \%}$ : secant tensile stiffness at $2 \%$ strain $(\mathrm{N} / \mathrm{m})$

$\bar{J}_{2 \%}$ : secant tensile stiffness at $2 \%$ strain mean value $(\mathrm{N} / \mathrm{m})$

$J_{5 \%}$ : secant tensile stiffness at $5 \%$ strain $(\mathrm{N} / \mathrm{m})$

$\bar{J}_{5 \%}$ : secant tensile stiffness at $5 \%$ strain mean value $(\mathrm{N} / \mathrm{m})$
$M_{A}$ : mass per unit area $\left(\mathrm{g} / \mathrm{m}^{2}\right)$

RCDW: Recycled Construction and Demolition Waste

$R F$ : global reduction factor

$R F_{C R}$ : creep reduction factor

$R F_{D}$ : durability reduction factor

$R F_{I D}$ : installation damage reduction factor

$R F_{M D}$ : mechanical damage reduction factor

$T_{a l}$ : allowable tensile strength

$\underline{T}_{u l t}:$ ultimate tensile strength

$\bar{T}_{u l t}$ : ultimate tensile strength mean value

$T_{\text {ult_v}}$ : ultimate tensile strength mean value of virgin (undamaged) samples

$T_{\text {ult_d}}$ : ultimate tensile strength mean value of damaged samples

$w_{o p}$ : optimum water content $(\%)$

USCS: Unified Soil Classification System

$\varepsilon_{\text {rup }}$ : strain or elongation at rupture mean value (dimensionless)

$\bar{\varepsilon}_{\text {rup }}$ : strain or elongation at rupture mean value (dimensionless) 